DOI 10.20396/ideias.v8i1.8649781

\title{
Esboçando uma teoria crítica da necessidade: apontamentos sobre a jovem Fraser $^{1}$
}

\author{
Enrico Paternostro Bueno da Silva
}

Resumo: O texto trata do modelo crítico de Nancy Fraser para uma teoria da necessidade, proposto em sua juventude. Recusando uma concepção essencialista, debruça-se antes sobre a "política de interpretação das necessidades", tratando do conflito discursivo que fundamenta políticas sociais. Através de interlocuções com Habermas, Gramsci e Foucault, o modelo aborda: a luta para pautar uma necessidade como demanda política legítima; a disputa sobre a interpretação das necessidades legitimadas por grupos e instituições sociais; e as maneiras pelas quais a burocracia estatal age em resposta ao propor políticas públicas para satisfazê-las.

Palavras-chave: Teoria Crítica; Necessidade; N. Fraser; Estado social.

\section{Outline for a critical theory of needs: Notes on the young Fraser}

Abstract: This paper addresses Nancy Fraser's critical model toward a theory of needs, formulated in her early works. Refusing an essentialist conception, she focuses rather on the "politics of need interpretation" and on the discursive conflict that grounds social policies. Dialoguing with Habermas, Gramsci and Foucault, her model deals with: the struggle to establish a need as a legitimate political claim; the dispute over the interpretation of needs legitimated by social groups and institutions; and the ways the State bureaucracy reacts to such needs, proposing public policies in order to meet them.

Keywords: Critical Theory; Needs; N. Fraser; Welfare state.

\footnotetext{
${ }^{1}$ Recebido em 15/08/2016 e aprovado em 15/02/2017.

2 Doutorando em Sociologia pela Universidade Estadual de Campinas (UNICAMP) e bolsista da Coordenação de Aperfeiçoamento de Pessoal de Nível Superior (CAPES). Contato: enricobueno@yahoo.com.br.
} 
|204|

Esboçando uma teoria crítica...

Esbozo de una teoría crítica de la necesidad: apuntes sobre la joven Fraser

Resumen: El texto trata sobre el modelo crítico de Nancy Fraser para una teoría de la necesidad, propuesta en su juventud. Al rechazar una concepción esencialista, analiza la "política de interpretación de las necesidades", tratando sobre el conflicto discursivo que fundamenta las políticas sociales. Mediante interlocuciones con Habermas, Gramsci y Foucault, el modelo aborda: la lucha para pautar una necesidad como reivindicación política legítima; la disputa sobre la interpretación de las necesidades legitimadas por grupos e instituciones sociales; y las maneras por las cuales la burocracia estatal actúa en respuesta, al proponer políticas públicas para satisfacerlas.

Palabras clave: Teoría crítica; Necesidad; N. Fraser; Estado social.

A filósofa Nancy Fraser é majoritariamente conhecida por suas contribuições às teorias da justiça e ao pensamento feminista. Percorrendo esses campos, sua produção nas últimas duas décadas - especialmente os textos que abrangem a celeuma com Axel Honneth acerca da teoria do reconhecimento (FRASER; HONNETH, 2003) - se consolidou como literatura indispensável para mapear certos temas e conceitos próprios da Teoria Crítica contemporânea. ${ }^{3}$ São pouco conhecidas, entretanto, suas valiosas contribuições de um momento anterior de sua carreira, aqui entendido como seu período de juventude (1980-1994). ${ }^{4}$ Nesse intervalo, além de realizar diálogos críticos que denunciam a omissão de Habermas quanto ao gênero e de esboçar uma aproximação com o pós-modernismo de Lyotard, a autora lançou

\footnotetext{
${ }^{3}$ Doravante, será utilizado o termo "Teoria Crítica” para se referir ao conjunto de autores que reivindicam herança teórica da chamada Escola de Frankfurt e dos princípios de teoria social que a caracterizam (HORKHEIMER, 1985). As expressões grafadas como "teoria crítica" ou "teorias críticas" se referem de modo mais abrangente a teorizações que assumem deliberado teor normativo ou reivindicam a tradição marxista mais amplamente.

${ }^{4}$ Conforme defendi em outro estudo (SILVA, 2013), é possível distinguir dois períodos da produção da autora: um primeiro, entre 1981 e 1994, em que se destaca a proposição de um modelo crítico para as disputas discursivas em torno das necessidades sociais; e um mais tardio, de 1995 em diante, no qual o quadro categorial se modifica e expande para uma teoria da justiça.
} 
alicerces para uma instigante teorização sobre as necessidades sociais, um dos temas centrais em seu primeiro livro, Unruly Practices (1989).

Esta breve apresentação de tal proposta se justifica por diversas razões: permite uma melhor compreensão dos fundamentos teóricos sobre o qual se erigiram os elementos de sua atual teoria da justiça; agrega indicativos conceituais para o estudo de políticas públicas, inclusive no Brasil contemporâneo; enriquece uma argumentação contraposta à teoria e ideologia liberais que visam consolidar o mérito como critério último da justiça social (MILLER, 1976). Considerando as possibilidades de contribuição da proposta, em face de sua pouca divulgação, almeja-se aqui traçar uma introdução ao modelo teórico da jovem Fraser. Tal modelo, na forma de um arcabouço sistemático, não é encontrado de modo definitivo em seus escritos, de modo que se provê aqui uma interpretação esquemática oriunda de uma variedade de textos aparentemente independentes entre si. Ao final do texto, buscar-se-á argumentar que este trabalho, sustentado sobre a herança teórica de Foucault, Habermas e Gramsci, pode ter rica serventia para a discussão do cenário sociopolítico brasileiro atual.

\section{Política de interpretação das necessidades}

As primeiras páginas de Unruly Practices já indicam o que Fraser entende por Teoria Crítica. Embora a proposta de Horkheimer esteja em seu horizonte, é sobre uma carta de Marx a Arnold Ruge que a autora busca fundamentar sua compreensão. Nela, o filósofo alemão afirma entender uma filosofia crítica como o autoentendimento das lutas e desejos de uma época (cf. MARX, 2010, p. 73). Fraser destaca o caráter político dessa concepção: uma filosofia crítica distinguir-se-ia de uma filosofia acrítica na medida em que projetasse sua pesquisa e seus conceitos tendo em vista os movimentos opositores às classes e grupos dominantes. Segundo ela, a proposição de Marx: 
|206|

Esboçando uma teoria crítica...

\begin{abstract}
integra três ideias sobre a relação entre teoria crítica e prática política: em primeiro lugar, valoriza as lutas conjunturais, historicamente específicas, como constituintes da agenda da teoria crítica; em segundo lugar, coloca os movimentos sociais como sujeitos da crítica; e em terceiro lugar, implica em que é na prática política que teorias críticas encontram seu teste final de viabilidade (FRASER, 1989, p. 2, trad. minha).
\end{abstract}

A um só tempo, essa interpretação justifica três aspectos fundamentais dos trabalhos da autora: sua preocupação em teorizar sobre a justiça social em interlocução com uma crítica imanente à atuação dos movimentos sociais, de modo especial o movimento feminista; o caráter abertamente crítico às formas multifacetadas de dominação e opressão que se incorpora em seu fazer teórico; e a sua preocupação com o discurso das necessidades, que no contexto de desmantelamento do Estado social norte-americano se mostra como tópico central na ordem do dia.

Pautando-se por influências diversas e não se restringindo aos pilares de Frankfurt, Fraser estabelece interlocuções com Foucault, Habermas e Gramsci para esboçar uma teoria crítica das necessidades - ou melhor, daquilo que ela denomina política de interpretação da necessidade (politics of need interpretation). Sua ambição não é alcançar uma conceituação sobre o reino da necessidade, ou tratá-lo sob algum registro essencialista, mas compreender o conflito em torno da definição, interpretação e formas de satisfação daquilo que, nas democracias ocidentais com Estado social, se convencionou chamar necessidades sociais. Especificamente, sua proposta é compreender como o discurso da necessidade é construído, interpretado e significado por agentes diversos, inclusive pelas instituições oficiais responsáveis pelas políticas de satisfação; é mostrar como grupos distintos e diversos constroem discursos visando politizar ou despolitizar uma necessidade assim definida; é, ainda, tratar de como as assimetrias de poder entre os atores atravessam os discursos, explicando como algumas definições e interpretações das necessidades são tidas como oficiais e legítimas em detrimento de outras. 
Fraser aponta que os estudiosos do tema costumam entender as reivindicações sob a seguinte estrutura: $a$ necessita de $x$ para poder $y$; argumentariam, por exemplo, que desabrigados necessitam de moradia para poder viver ou mães solteiras necessitam de auxílio financeiro para poder sustentar seus filhos, etc. A autora indica quatro principais problemas nas teorias que se sustentam sobre esta fórmula: 1) a interpretação das necessidades seria tomada como estabelecida e não-problemática, supondo que o objeto de disputa são apenas os benefícios e obstruindo a dimensão interpretativa das políticas sociais; 2 ) os agentes que interpretam as necessidades, suas perspectivas e interesses, não importariam a estas teorias, pois não tocariam na questão da dificuldade em se estabelecer definições dominantes e autorizadas para as necessidades; 3) tais teorias suporiam que "as formas socialmente autorizadas de discurso público disponíveis para interpretar as necessidades das pessoas são adequadas e justas" (FRASER, 1989, p. 164), não questionando se estas formas de discurso público favorecem autointerpretações e interesses dos grupos dominantes em detrimento de grupos subordinados ou opositores; negligenciariam, assim, o fato de que os próprios meios discursivos são passíveis de questionamentos; 4) deixariam de problematizar a lógica institucional e social do processo interpretativo e ignorariam, com isso, as instituições que desenvolvem as interpretações dominantes e como elas se relacionam com seus interlocutores.

Em suma, as teorias assim formuladas não tocariam na complexa cadeia de disputas que cada reivindicação engendra. No caso dos sem-teto, a autora enumera uma grande variedade de questões que envolvem a significação da necessidade: de que necessitam os que passam frio? Deve-se propiciar albergues temporários ou casas permanentes? Quais medidas devem ser tomadas após a alocação em abrigos? Deve-se subsidiar aluguéis, oferecer moradia permanente, alocar o atendido em alguma política de geração de emprego? Deve-se exigir dos beneficiados a participação em políticas de capacitação profissional e educação formal? As perguntas poderiam se multiplicar. Importa visualizar que a definição de uma necessidade abrange complexas visões 
|208|

Esboçando uma teoria crítica...

de mundo acerca de identidades, vontades e projetos, com reivindicações específicas que se vinculam em cadeias de relações.

Ao falar em "política de interpretação da necessidade", Fraser se refere exatamente à ampla e disputada rede de relações condicionadas que perpassa os discursos em um debate sobre a necessidade. A autora assume, assim, a complexidade de todo processo de formulação, interpretação e satisfação de uma necessidade, em que agentes diversos - movimentos sociais, grupos de interesse, burocratas - emitem discursos controvertidos na esfera pública buscando afirmar e consolidar seu entendimento. Dessa forma, sua perspectiva quer colocar em questão o discurso hegemônico sobre as necessidades, lançando olhar ao contradiscurso oposicional, contestatório da definição e interpretação oficial, veiculado no que ela chama de contrapúblicos subalternos. Para a autora, "o tema das necessidades funciona como um meio para realizar e debater as reivindicações políticas; é um jargão pelo qual se dá o conflito político e através do qual as desigualdades são simbolicamente elaboradas e disputadas" (FRASER, 1989, p. 161-162, trad. minha). Daí a importância de não examinar apenas a política de necessidade - a distribuição de benefícios a partir de uma noção já dada - mas olhar para a disputa anterior no plano discursivo.

Nesse registro, o estudo da luta contestatória deve contemplar um sentido amplo e pretensioso: não se trata apenas de reivindicações por políticas públicas pontuais ou alterações legislativas, mas também de processos que visam transformação da cultura política por meio da reestruturação das definições e interpretações dominantes, legítimas, enfim, hegemônicas das necessidades (FRASER, 2010). A contestação não impacta apenas instituições políticas, mas também se volta para o plano das "concepções de mundo" - para usar outro termo gramsciano -, para o vocabulário e os entendimentos hegemônicos e legítimos inscritos nos discursos. 


\section{Os meios socioculturais de interpretação e comunicação}

Em face deste objeto, ainda fica em aberto a questão de como o modelo crítico de Fraser pode dar conta das disputas em questão. Que aspectos devem ser observados? De que modo se dá o aspecto crítico nesse tratamento? Para responder, a autora acredita que é preciso conceber uma distinção entre três momentos fundamentais em uma luta por necessidades. Os momentos são analiticamente distintos, mas interrelacionados na prática. Não se dão necessariamente em certa ordem cronológica, mas supõem aspectos distinguíveis metodologicamente:

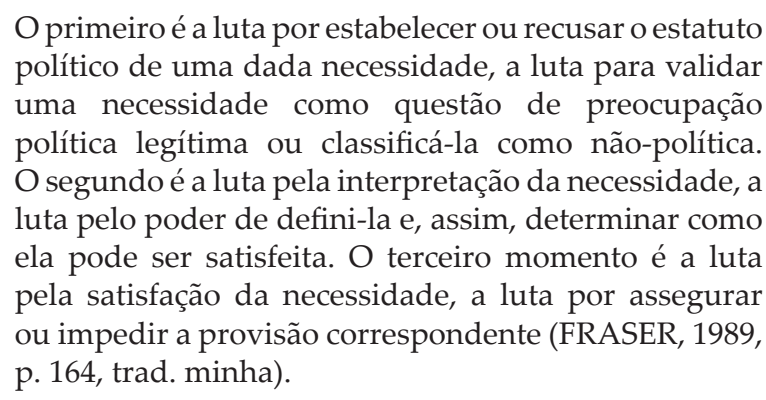

O primeiro é a luta por estabelecer ou recusar o estatuto político de uma dada necessidade, a luta para validar uma necessidade como questão de preocupação política legítima ou classificá-la como não-política. O segundo é a luta pela interpretação da necessidade, a luta pelo poder de defini-la e, assim, determinar como ela pode ser satisfeita. O terceiro momento é a luta pela satisfação da necessidade, a luta por assegurar ou impedir a provisão correspondente (FRASER, 1989, p. 164, trad. minha).

O trabalho de Fraser teoriza principalmente sobre o segundo aspecto, ainda que nos momentos em que a autora se propõe a aplicar seu modelo, os três sejam trabalhados, dado que são interrelacionados. Na crítica do conflito pela interpretação da necessidade, a jovem Fraser indica que é preciso olhar para o "conjunto específico, cultural e histórico, de recursos discursivos disponíveis aos membros de uma dada coletividade social em reivindicação contra uma outra" (FRASER, 1989, p. 164, trad. minha). A este conjunto ela denomina "meios socioculturais de interpretação e comunicação" (sociocultural means of interpretation and communication), abreviado como MIC. No último capítulo de Unruly Practices, são enumerados cinco MIC que devem ser observados em um conflito político relativo às necessidades. São eles: a) as formas de expressão oficialmente reconhecidas pelas 
|210 |

Esboçando uma teoria crítica...

quais é possível travar uma reivindicação (um discurso político, não sendo aleatório, se enquadra dentro das formas de expressão reconhecidas em um dado contexto sociocultural e político; exemplo: discurso do interesse, das necessidades, do direito, do mérito, etc.); b) os vocabulários disponíveis para tratar das demandas em expressões reconhecíveis, ou seja, o conjunto de expressões e significados que estão disponíveis a uma coletividade que, em dado contexto sociocultural, se pretende colocar em um embate político (como vocabulário socialista, religioso, feminista, jurídico, etc.); c) os paradigmas argumentativos aceitos como autorizados a julgar reivindicações em conflito: pode ser pelo apelo a especialistas científicos, à maioria, pelo privilégio dado ao discurso das pessoas cuja necessidade está em questão, etc.; d) as convenções narrativas disponíveis para a construção de histórias constitutivas das identidades sociais dos indivíduos e coletividades em debate (como narrativas do tipo épica, romântica, dialética, psicanalítica, dentre outras); e) as formas de subjetivação, maneiras pelas quais os vários discursos constituem aqueles aos quais se dirigem como sujeitos específicos, dotados de capacidades específicas para a ação. Em outro escrito, Fraser (1986) traz ainda mais dois meios que devem ser contemplados por este modelo: f) o repertório de recursos retóricos disponíveis; e g) as dimensões corporais e gestuais da fala que se associam a uma determinada cultura.

Temos, portanto, sete recursos que permeiam o discurso político no capitalismo tardio, incluindo o discurso sobre a necessidade. Mais que analisar, em cada conflito, como são mobilizados esses recursos, Fraser descortina a necessidade de criticá-los, de mostrar os caminhos pelos quais são concebidos e organizados de forma a dar voz às experiências, interesses e autointerpretações dos grupos dominantes. Em um curto e significativo artigo no qual dialoga com Habermas e Seyla Benhabib, a autora postula justamente os MIC enquanto expressão da hegemonia instituída: 


\begin{abstract}
em sociedades sexistas, racistas e classistas, mulheres, negros, pobres e outros grupos dominados estariam em posição de desvantagem no que diz respeito aos meios socioculturais de interpretação e comunicação. Eles estariam estruturalmente impedidos de participarem como um par com membros dos grupos dominantes em processos de interação comunicativa. A menos que contestassem sua situação e se organizassem para conquistar algum controle coletivo sobre os meios de interpretação e comunicação, pareceria que eles teriam apenas duas opções: adotar o ponto de vista dominante e ver suas próprias experiências reprimidas e distorcidas; ou desenvolver idioletos capazes de dar voz às suas experiências e as verem marginalizadas, desqualificadas e excluídas das instituições e arenas discursivas centrais da sociedade (FRASER, 1998, p. 426, trad. minha).
\end{abstract}

Assim, nas arenas discursivas centrais das "democracias modernas" - não só nas arenas da esfera pública burguesa, mas também nas arenas discursivas no interior do Estado, que Fraser chama de "públicos fortes" -, os recursos discursivos hegemônicos e legítimos são justamente aqueles que favorecem a visão de mundo das classes e grupos dominantes. Daí a importância do conceito de contrapúblicos subalternos: públicos excluídos do debate oficial e legitimado na esfera pública burguesa, que necessitam circular seus discursos em espaços paralelos e marginais, a fim de se prepararem, se fortalecerem e conquistarem espaço para o debate nas arenas centrais da sociedade moderna.

Sua crítica convida, assim, a olhar para como certos grupos ou classes dominantes são favorecidos pelos MIC enraizados na cultura política das sociedades ditas avançadas. Seu modelo crítico visa articular discurso político, desigualdade e assimetrias de poder (este concebido em sentido lato e capilarizado, seguindo a filosofia foucaultiana). O discurso sobre as necessidades não supõe apenas uma diversidade de agentes, mas uma complexa estratificação entre eles em vários sentidos: são recortados em grupos com status, acesso a recursos e poder político desiguais; atravessados por 
desigualdades de classe, gênero, "raça", etnicidade. Dito de outro modo: se dentro de uma sociedade estratificada há diferenças culturais nas formas dos diversos agentes se expressarem gama lexical, paradigmas de argumentação, postura corporal e gestual, etc. -, caberia demonstrar de que maneiras determinadas formas são construídas como recursos discursivos inferiores em face de outras; ou seja, demonstrar que as formas de expressão dos subalternos, marginalizados e excluídos são desvalorizadas e deslegitimadas enquanto recursos discursivos para definir, interpretar e reivindicar uma necessidade.

Nessa constatação de que olhar para a desigualdade - em seus múltiplos cruzamentos - é fundamental quando se quer tratar dos discursos políticos em conflito, Fraser se vale em muitos momentos de termos como "hegemonia", "hegemônico", "contra-hegemônico", inspirados em Gramsci. A noção é trazida no conjunto de escritos que ficou conhecido como "Cadernos do Cárcere", em especial nos textos agrupados no livro recebeu o nome de Concepção dialética da história (GRAMSCI, 1984). Ela nos leva a conclusões relevantes no que se refere à luta política pela transformação social. Especialmente, mostra que a mudança social transformadora não ocorre por uma luta apenas referida ao Estado (pela tomada do poder ou pela influência sobre ele), mas que também exige a difusão de novas concepções de mundo ao longo de uma sociedade, provocando transformações em sua cultura política. Em um projeto político transformador - socialista, democrático e plural, na pretensão de Fraser - construir uma nova hegemonia envolve a formulação autônoma, pelos grupos governados, de uma concepção de mundo crítica, em uma luta político-cultural contrária à concepção de mundo imposta pelos grupos atualmente dominantes.

"Hegemonia" é o termo do marxista italiano Antonio Gramsci para a face discursiva do poder. É o poder de estabelecer o "senso comum" ou a "doxa" de uma sociedade, ou seja, a base das concepções autoevidentes da realidade social, normalmente não verbalizadas. A hegemonia, assim, expressa a posição 


\begin{abstract}
favorável dos grupos sociais dominantes em relação ao discurso. [...] No entanto, isso não implica que o conjunto de concepções que circulam na sociedade compreende uma teia monolítica e contínua. Pelo contrário, a "hegemonia" designa um processo em que a autoridade cultural é negociada e disputada. Ela pressupõe que as sociedades contêm uma pluralidade de discursos e espaços discursivos, uma pluralidade de posições e perspectivas a partir das quais se exerce a fala (FRASER, 1990a, p. 95, trad. minha).
\end{abstract}

O conceito de hegemonia se revela essencial ao modelo da jovem Fraser na medida em que permite a vinculação teórica entre desigualdade, discurso e assimetrias de poder; contribui, assim, ao tratamento da complexidade dos discursos e concepções que circulam na sociedade e dos conflitos políticos travados pelos agentes que visam a construção de uma "autoridade cultural", seja por parte dos grupos dominantes - que querem ratificar os MIC que lhes favorecem -, seja por parte dos grupos dominados - que querem questionar a autoridade cultural hegemônica. Enfim, essa apropriação do conceito de hegemonia não só auxilia no tratamento das políticas de interpretação da necessidade como também alerta que a esfera pública - segundo o registro habermasiano ${ }^{5}$ - pode ser o palco em que o discurso contra-hegemônico (após ser fortalecido e consolidado entre os contrapúblicos) é posto em debate, problematizando a hegemonia e/ou dominação instituídas.

Dessa forma, Fraser articula Habermas e Gramsci em seu modelo a fim de tratar das desigualdades entre os agentes que

\footnotetext{
${ }^{5} \mathrm{O}$ conceito de esfera pública é oscilante ao longo da produção de Jürgen Habermas, com nuances visíveis em obras como Mudança estrutural da esfera pública, Teoria do agir comunicativo e Direito e democracia. O núcleo comum do conceito, grosso modo, remete às arenas da vida social onde grupos ou pessoas privadas desenvolvem argumentos mediante razões de modo a colocar em questão os consensos morais estabelecidos no tecido social, podendo (ou não) resultar na substituição de visões de mundo ancoradas em tradições não reflexivas por entendimentos normativos comunicativamente alcançados.
} 
conflitam, negociam e constroem consensos. Com efeito, o diálogo entre os dois autores é geralmente implícito, mas se torna claro, por exemplo, quando utiliza "hegemônico" e "contra-hegemônico" para designar os diversos posicionamentos políticos colocados em debate público. Em uma nota de "Rethinking the Public Sphere", a autora torna essa articulação explícita e parece conceber de maneira semelhante o conceito habermasiano de "opinião pública" e o gramsciano de "senso comum":

A esfera pública produz consenso pela circulação de discursos que constroem o "senso comum" do dia e representam a ordem existente como natural e/ ou apenas, mas não simplesmente, uma armadilha imposta. Ainda, a esfera pública em sua forma madura inclui participação e representação suficientes de interesses múltiplos que permitem a muitas pessoas, na maioria das vezes, se reconhecerem a si próprias nesses discursos. (FRASER, 1990b, p. 78, trad. minha).

Em suma, é possível alcançar, desta proposta, alguns indicativos para um estudo crítico de tais disputas. Ele envolveria: a) a distinção analítica de três aspectos em um conflito a respeito de uma necessidade: a luta pela construção de uma necessidade enquanto tal; a luta por sua definição e interpretação; e a luta por sua satisfação; b) análise e crítica dos MIC em uma dada sociedade no que se refere à necessidade em conflito; c) análise e crítica da variedade dos grupos sociais que se colocam em conflito e as desigualdades que os atravessam; d) tratamento da relação entre grupos sociais e seus traços culturais - sobretudo no plano linguístico - desigualmente valorizados quando confrontados na esfera pública; e) tratamento dos discursos diversos sobre as necessidades veiculados na esfera pública, considerando as desigualdades que os permeiam; f) tratamento da interpretação oficial da necessidade reivindicada e sua satisfação por meio de políticas públicas. 


\section{Movimentos sociais $\mathrm{x}$ burocracias estatais}

Um aspecto que merece aprofundamento é a ideia da autora segundo a qual há discursos - geralmente hegemônicos e naturalizados - que tendem a despolitizar uma necessidade, enquanto outros - muitas vezes contra-hegemônicos e contestatórios - buscam tratar essa mesma necessidade enquanto tema eminentemente político. Dessa noção, emergem algumas questões: o que entende autora por "político" e "política"? Como tratar dos limites entre as dimensões do "político", do "econômico" e do "doméstico" - esferas que ela concebe mais como "classificações culturais" ou "etiquetas ideológicas" do que como estruturas dadas - no que tange à cultura política das sociedades de capitalismo tardio?

Nos textos analisados, a jovem Fraser opta por uma concepção bidimensional, inspirada em Habermas: a política envolve simultaneamente uma dimensão institucional e outra discursiva. A primeira se refere às instituições e procedimentos oficiais de tomadas de decisão (parlamento, aparelhos administrativos, agências estatais, etc.); tomado o termo nesse sentido, um assunto é político na medida em que é debatido e manejado por tais instituições; ou, para usar o jargão habermasiano, o tema é tido como político na medida em que é tratado pelo subsistema administrativo. A segunda dimensão, discursiva, remete à concepção já trabalhada de esfera pública, segundo a qual uma concepção ampliada de democracia exige que os problemas percebidos na vida ordinária e discutidos na arena pública sejam canalizados à institucionalidade estatal e dela obtenham uma resposta efetiva. O horizonte dessa concepção é a imbricação entre as duas dimensões: um determinado tema só se torna sujeito à intervenção estatal legítima quando atravessa o crivo da opinião pública. Desse modo, não há restrições a priori para classificar um assunto como político ou não, mas é o próprio debate público que construirá a definição.

Grosso modo, esse tipo de debate pode apresentar duas tendências em disputa. De um lado teríamos grupos dominantes, 
que tendem a classificar certos temas como pertinentes ao "doméstico" ou ao"econômico" -impedindo, assim, sua politização. Ao encerrarem temas em seus territórios discursivos, instâncias domésticas e econômicas os protegem de um questionamento generalizado e de conflitos amplos, cravando como hegemônicas certas interpretações específicas sobre as necessidades e limitando assim as já referidas cadeias de relações condicionadas. Do outro lado estariam os grupos subalternos organizados coletivamente, trabalhando para que tais temas sejam encarados como questões políticas, necessidades a serem debatidas publicamente e resolvidas politicamente. A jovem Fraser não chega a teorizar profundamente sobre as condições nas quais os movimentos sociais e outros atores oposicionais conseguem politizar um tema, mas trata o assunto da seguinte forma:

\begin{abstract}
Algumas vezes interpretações culturalmente dominantes sobre as necessidades são sobrepostas por interpretações oposicionais, latentes ou embrionárias. Isto acontece sobretudo onde persistem, ainda que de modo fragmentado, tradições de resistência transmitidas culturalmente, como em certos setores do movimento operário estadunidense e na memória histórica de muitos afro-americanos. Ademais, sob circunstâncias especiais, difíceis de teorizar especificamente, processos de despolitização são interrompidos. Nesse momento, classificações dominantes de necessidades como "econômicas" ou "domésticas" - opostas à "política" - vêm a perder sua autoevidência, surgindo em seu lugar interpretações alternativas, opostas e politizadas (FRASER, 1989, p. 169, trad. minha).
\end{abstract}

Dessa maneira, conforme emerge um vocabulário político das necessidades - e uma linguagem contestadora a seu respeito - constrói-se uma permeabilidade nas instituições domésticas e econômicas que as torna incapazes de despolitizar certos temas. As necessidades que escapam a este processo de despolitização são 
denominadas pela autora como "necessidades fugidias" (runaway needs), ganhando a possibilidade de ampliarem suas cadeias de relações condicionadas. Ao deixar os encraves do "doméstico" ou do "econômico", as necessidades fugidias adentram o território que Fraser chama, com base em Hannah Arendt, de "social": uma arena que não coincide com a família, a economia oficial ou o Estado.

Ao trazer o "social" como quarta etiqueta classificatória, Fraser está chamando a atenção para uma mediação necessária no processo discursivo de interpretação das necessidades: um tema antes aprisionado, pelo discurso hegemônico, a classificações privatizantes (enquanto questão "doméstica" ou "econômica") não se torna espontaneamente objeto de manejo institucional sob a forma de políticas públicas. Antes de alcançar esse estatuto político, as necessidades se tornam objeto de conflito entre atores diversos, que mobilizam projetos políticos conflitantes e se pautam por formações discursivas opostas. É por meio dessa polêmica pública que as necessidades podem escapar à despolitização pretendida por determinados grupos, os quais, em função de visões de mundo ou interesses, visam impedir esse processo.

Para Fraser, então, o "social" se refere ao território do conflito entre as interpretações rivais de necessidades, que se encontram em cadeias de relações opostas entre si, onde as necessidades fugidias se politizam e se transformam em reivindicações para a ação governamental. Dizer que um tema, através das disputas por essas classificações culturais, alçou o estatuto de "questão social" significa dizer que ele já se tornou objeto da polêmica pública enquanto problemática que transcende âmbitos privatizantes (econômico ou doméstico); isto é, que ele já é "político" - mas apenas naquele sentido discursivo, pois ainda não se converteu em medida institucional concreta. Nessa esfera do "social", diz Fraser, "as interpretações rivais sobre as necessidades se transformam em concepções paradigmáticas rivais; as alianças rivais se constituem ao redor de propostas políticas rivais; e os grupos desigualmente dotados competem para construir a agenda política formal" (FRASER, 1989, p. 170, trad. minha). O "social" é, em suma, 
o espaço onde as necessidades que já são tidas como questão pública, do ponto de vista discursivo, tornam-se candidatas a intervenção legítima do Estado; onde elas, depois de ganharem espaço na agenda política discursiva e informal, buscam espaço na agenda formal da administração governamental. Assim, libertando-se das etiquetas "domésticas" ou "econômicas" pela luta organizada dos movimentos sociais, uma necessidade fugidia é aquela que passa a ser vista como "questão social" pelo senso comum, até que finalmente se torne uma "questão política", objeto de políticas públicas.

Para melhor compreender essa disputa classificatória, é preciso elencar os principais tipos de discurso sobre as necessidades identificados e tratados pela jovem Fraser. Primeiramente, haveria os discursos opositores, veiculados principalmente nos contrapúblicos subalternos por seus atores organizados coletivamente, sobretudo os movimentos sociais. Neles, as necessidades são politizadas a partir das bases, de forma a também autoconstituirem os sujeitos que as politizam, colocando em cheque as formas de subjetivação trazidas implicitamente nas políticas públicas de necessidade. Ademais, ao buscar status político para suas necessidades, os grupos e atores simultaneamente: questionam os limites entre o "político", o "social", o "doméstico" e o "econômico", oferecem interpretações alternativas, criam novos públicos para os discursos e questionam os MIC hegemônicos.

Em oposição aos discursos opositores, e de forma bastante característica da agenda neoliberal, estariam os discursos reprivatizadores. Estes visam desmantelar ou reduzir os serviços de bem-estar social e desregular a empresa privada, em favor da ampliação da liberdade de mercado e do enxugamento do Estado. Mas não apenas isso: esse tipo de discurso pode insistir que a questão dos maus tratos à mulher, por exemplo, é pertinente ao "doméstico"; e o fechamento de uma fábrica ao "econômico". Com isso, contribuem para a despolitização, uma vez que tentam trazer aos âmbitos privados do "econômico" ou do "doméstico" 
determinadas questões e necessidades levantadas por movimentos sociais de resistência.

A existência dessas duas tendências de discurso já estava presumida até aqui. A terceira tendência, contudo, diz respeito ao momento em que tais necessidades já tidas como "sociais" se prestam ao manejo das instituições oficiais. Trata-se, assim, dos discursos de especialistas, que buscam traduzir necessidades fugidias, politizadas, em intervenção estatal. São discursos acadêmicos das várias áreas do conhecimento, discursos legalistas veiculados por instituições jurídicas, discursos administrativos que circulam nas agências do Estado social e até discursos terapêuticos, veiculados em agências médicas e de serviço social. Todos buscam caminhos para traduzir a necessidade politizada em política pública. Mediante a vinculação eventual que os movimentos sociais podem travar com agentes especialistas ou mediante a capacidade de crítica desses movimentos frente a tais discursos, estes podem adquirir certa porosidade. Em outras palavras, esses discursos podem constituir uma ponte entre os movimentos sociais organizados com o Estado social.

Estes três tipos de discurso entram costumeiramente em conflito quando se trata das políticas de necessidades. A partir das formulações de Fraser, pode-se enumerar três principais eixos em que esses conflitos são travados, que correspondem aos três momentos da constituição de uma política de necessidades.

No primeiro eixo, que trata do conflito pela legitimidade política da necessidade, costumeiramente entram em conflito os dois primeiros tipos de discurso. De um lado, discursos opositores tentam politizar necessidades e colocá-las à administração política, reivindicando direitos e políticas públicas para solucionar questões antes relegadas ao âmbito do "doméstico" e do "econômico". Do outro lado, discursos reprivatizadores se opõem às medidas governamentais que legitimam a politização das necessidades fugidias. Buscam deslegitimá-las, afastá-las da política, relegando-as ao âmbito do privado.

O segundo eixo se refere à luta por tornar hegemônica uma dada interpretação da necessidade. Uma vez que uma necessidade 
fugidia conseguiu ser politizada, o conflito é travado em torno da interpretaçãode seu conteúdo. Deumlado, colocam-seatores contrahegemônicos; de outro, interesses organizados, principalmente de corporações, que buscam influenciar no planejamento de políticas. Assim, por exemplo, uma vez politizada a necessidade de moradia, o conflito discursivo se refere a como interpretar a necessidade: reivindica-se moradia própria a todos? No centro da cidade? Nas periferias? Aluguéis mais baratos? Financiamentos com juros reduzidos? Subsídios estatais? Reforma urbana radical? Grupos distintos, opositores e reprivatizadores, debaterão na esfera pública suas interpretações sobre as necessidades, visando construir suas concepções como hegemônicas.

O terceiro eixo, enfim, diz respeito à luta pela efetivação de políticas públicas que satisfaçam as necessidades em debate. Aqui, o conflito se dá principalmente entre os movimentos opositores que conseguiram politizar uma necessidade e os "especialistas" do Estado que indicarão como concretizá-las em forma de políticas públicas e, dessa forma, passarão a tratar uma necessidade politizada por uma coletividade específica com uma retórica administrativa:

Estes discursos consistem em uma série de operações de reescritura, procedimentos que traduzem as necessidades politizadas em necessidades administrativas. Tipicamente, a necessidade politizada é redefinida como o correlativo de um benefício que pode ser administrado burocraticamente, de um "serviço social". É especificada em termos de um conjunto de circunstâncias que, a princípio, poderia corresponder a qualquer pessoa: por exemplo, desemprego, deficiência física ou deserção de um cônjuge. Como resultado, a necessidade é descontextualizada e recontextualizada: por um lado, é representada abstraindo qualquer especificidade de classe, raça, gênero e qualquer significado opositor que possa ter adquirido no curso de sua politização; 


\begin{abstract}
por outro, é interpretada em termos que pressupõem tacitamente um contexto institucional arraigado, como trabalho assalariado ("primário"), o cuidado infantil privatizado ("secundário") e sua separação pautada pelo gênero (FRASER, 1989, p. 174, trad. minha).
\end{abstract}

Com as abstrações realizadas nesse processo de descontextualização e recontextualização, os requerentes que lutaram pela politização deixam de ser vistos como sujeitos políticos dotados de determinadas características (de classe, etnia, gênero, etc.), sendo encarados pelo sistema de assistência como casos individuais de uma necessidade genérica. São tomados como beneficiados, indivíduos passivos, "clientes" do Estado, abstraindo seu caráter de agente envolvido na interpretação das próprias necessidades. Habermas, na Teoria do agir comunicativo, havia tratado deste processo ao discutir as tendências de juridificação no Estado Social e a construção do papel social do cidadão enquanto cliente; segundo ele, no enfrentamento administrativo do problema social que reivindica uma pretensão jurídica, "a situação carente de regulamentação [...] tem de ser submetida a uma violenta abstração, não apenas porque ela tem de ser submetida ao direito, mas também para que ela possa ser enfrentada de um ponto de vista administrativo" (HABERMAS, 2012, p. 652). Por isso, neste último eixo de conflito, Fraser entende que o discurso de especialistas tende a, novamente, tentar despolitizar a necessidade. Por sua vez, atores sociais lutarão para evitar essa nova despolitização.

Trata-se de uma disputa complexa, constante, que não encontra estabilização definitiva. A todo tempo, instituições privadas e a burocracia estatal agem em sentido despolitizante, seja por meio dos discursos reprivatizantes ou de especialistas. $\mathrm{Na}$ árdua e gradual tarefa de se construir uma nova hegemonia, as coletividades subalternas organizadas, já em desvantagem pela desigualdade multifacetada que lhes afeta, travam um longo conflito para impor como legítimas suas interpretações das próprias necessidades. 
|222 |

Esboçando uma teoria crítica...

O modelo crítico da jovem Fraser, portanto, quer alertar para a complexidade da questão da necessidade: quer recusar um materialismo extremado que ignora a dimensão e simbólica contida em uma necessidade material; quer contestar uma noção apriorística do conceito de necessidade, ao tomá-lo como construção que envolve conflitos de interpretação; mas também quer combater uma construção unilateral dos aparatos do regime discursivo vigente, alertando para as contrainterpretações veiculadas.

\section{Breves conclusões}

Diante deste instigante modelo crítico, algumas considerações são necessárias, de modo a ponderar a pertinência, atualidade e força da formulação.

Primeiramente, um elemento de força da proposta é sua busca por historicização da discussão sobre necessidades, colocando a definição e interpretação como resultantes de lutas sociais e não como um dado autoevidente ou de fundo metafísico. Seu combate a concepções essencialistas é elemento de relevo para justificar seu trabalho enquanto crítico, segundo a acepção frankfurtiana para o termo.

Em segundo lugar, ao propor uma teoria crítica que coloca em voga o plano discursivo do conflito social - a fim de compreender o processo de constituição de identidades e significados que permeiam as relações sociais, vinculando-os a condicionantes estruturais e coerções materialmente fundadas -, Fraser traça um diálogo abrangente com outras vertentes do pensamento filosófico, como a teoria foucaultiana do discurso ${ }^{6}$ e o marxismo heterodoxo

\footnotetext{
${ }^{6}$ A influência de Foucault, menos aprofundada nesse trabalho, é revelada pela simpatia expressa da autora pelo procedimento genealógico, influente sobre sua abordagem antiessencialista, e pela concepção capilarizada de poder (cf. FRASER, 1989, p. 17-34). Não é casual que, como epígrafe de seu principal texto à época, Fraser mobilize uma citação de Vigiar e punir que traz o discurso da necessidade como instrumento do regime moderno de saber-
} 
de Gramsci, alcançando uma interlocução rica e condizente com o pensamento social de seu tempo. Dessa maneira, Fraser esforça-se para não cair em um ecletismo confuso, tentando organizar, em um arcabouço razoavelmente coeso, elementos conceituais de diversas origens e conclusões obtidas de estudos empíricos - sobretudo que tratam das políticas públicas voltadas à mulher nos Estados Unidos. Esse esforço, entretanto, nem sempre é bem-sucedido; particularmente, há alguma inconsistência nos momentos em que busca integrar conceitos de Habermas e Gramsci, sem dedicar alguns parágrafos a uma explicação teórica da interlocução. Por exemplo, conceitos inseridos em quadros teóricos originalmente distintos - como "senso comum" e "opinião pública" - parecem intercambiáveis nos textos da autora sem uma consideração teórica que justifique a opção. Além disso, a tensão conceitual entre o momento negativo do conflito e a construção positiva do consenso, tratada diferentemente pelos dois autores, não é devidamente desenvolvida no seio dessa interlocução teórica. Por fim, a abrangência do diagnóstico de época realizado é incerta, uma vez que pretende dar conta das políticas de necessidade nas "democracias capitalistas avançadas com bem-estar social" (dispensando maiores definições) mas tem seu enraizamento empírico excessivamente localizado na realidade norte-americana.

A despeito das fragilidades, a proposta de Fraser pode ser contributiva para pensar as políticas públicas no Brasil contemporâneo, principalmente aquelas desenvolvidas no ciclo petista e que têm sido objeto crescente de estudo. Com efeito, o proveito de tal aparato pode apontar para uma interpretação dos princípios, procedimentos e consequências envolvidos nas políticas sociais de distribuição de renda, moradia, combate

poder; segundo o trecho, "a necessidade é também um instrumento político cuidadosamente organizado, calculado e utilizado" (FOUCAULT, 2008, p. 26). Ao contrário do filósofo francês, entretanto, a formulação de Fraser adota um caráter abertamente normativo em sua crítica dos meandros discursivos da dominação e alinha sua teorização aos movimentos de resistência, seguindo aquela intuição marxiana. 
à violência doméstica, etc., transcendendo a ênfase quantitativa e estatística e visando uma compreensão crítico-qualitativa que coloque em questão as interpretações de identidades e significados que subjazem às políticas. Em análises conjunturais, o arcabouço pode ainda ser mobilizado: para discutir a dimensão discursiva e ideológica do conflito distributivo que se acirrou nos últimos anos e culminou no aprofundamento das políticas de austeridade após a deposição de Dilma Rousseff; para embasar um diagnóstico atual quanto ao papel dos meios de comunicação em massa - muitos deles controlados por poderosos grupos de interesse ou vinculados a congressistas $^{7}$ - para a reafirmação de MICs que favorecem a reprodução da subordinação discursiva de determinados grupos e classes; ou para a análise crítica dos discursos privatizadores, próprios de um "liberalismo conservador" que crescentemente circula em camadas da classe média (cf. CAVALCANTE, 2015).

Em suma, é plausível considerar que o modelo crítico para as políticas de interpretação da necessidade (com os devidos aprofundamentos teóricos, e atualizações) possa ser contributivo para uma sociologia da proteção social e para uma teoria social crítica que ajude a localizar os elementos regressivos contidos em estruturas e relações sociais contemporâneas. Diante disso, a adaptação da proposição da jovem Fraser aparece como desafio instigante à teoria e prática política no Brasil atual.

\section{Referências}

CAVALCANTE, Sávio. Classe média e conservadorismo liberal. In: VELASCO E CRUZ, S.; KAYSEL, A.; CODAS, G. (orgs.). Direita,

\footnotetext{
${ }^{7}$ Segundo o relatório do Portal Excelências, da Transparência Brasil, os congressistas concessionários de rádio e televisão representam 8,4\% da Câmara (43 deputados) e 23,5\% do Senado (19 senadores) (cf. TRANSPARENCIA BRASIL, 2016). A ocorrência de congressistas ligados a concessões públicas de comunicação social contraria o artigo 54 da Constituição Federal.
} 
volver: O retorno da direita e o ciclo político brasileiro. São Paulo: Fundação Perseu Abramo, 2015.

FOUCAULT, Michel. Vigiar e punir: Nascimento da prisão. Trad. Raquel Ramalhete. Petrópolis: Vozes, 2008.

FRASER, Nancy. What's Critical about Critical Theory? The Case of Habermas and Gender. New German Critique, n. 35, 1985.

Movimientos Sociales vs. Burocracias Disciplinarias: los discursos de las necesidades sociales. Trad. Adriana Sandoval. Dianoia, n. 32, p. 167-202, 1986.

Unruly Practices: Power, Discourse, and Gender in Contemporary Social Theory. Minneapolis: University of Minnesota Press, 1989.

The Uses and Abuses of French Discourse Theories for Feminist Politics. Boundary 2, vol. 17, n. 2, p. 82-101, 1990a.

Rethinking the Public Sphere: A Contribution to the Critique of Actually Existing Democracy. Social Text, n. 25/26, p. 56-80, 1990 b.

. Toward a Discourse Ethic of Solidarity. In: GATENS, Moira (org.). Feminist Ethics. Brookfield: Ashgate, 1998, p. 269-274.

. Solidariedade ou singularidade? Richard Rorty entre o Romantismo e a tecnocracia. Trad. Susana de Castro. Redescrições, ano 2, n. 1, 2010.

FRASER, Nancy; GORDON, Linda. Contrato vs. Caridade: Por que não existe cidadania social nos Estados Unidos? Trad. Angela Maria Moreira. Revista Crítica de Ciências Sociais, n. 42, p. 27-52, 1995.

FRASER, Nancy; HONNETH, Axel. Redistribution or Recognition? A Political-philosophical Exchange. London: Verso, 2003.

GRAMSCI, Antonio. Concepção dialética da história. Trad. Carlos Nelson Coutinho. Rio de Janeiro: Civilização Brasileira, 1984. 
|226 |

Esboçando uma teoria crítica..

HABERMAS, Jürgen. Teoria do agir comunicativo, volume 2: Sobre a crítica da razão funcionalista. Trad. Flávio Beno Siebeneichler. São Paulo: WMF Martins Fontes, 2012.

HORKHEIMER, Max. Teoria Tradicional e Teoria Crítica. In: Horkheimer \& Adorno, coleção Os Pensadores. Trad. Edgard Afonso Malagodi e Ronaldo Pereira Cunha. São Paulo: Nova Cultural, 1991.

MARX, Karl. Cartas dos Anais Franco-Alemães. In: Sobre a questão judaica. Trad. Nélio Schneider. São Paulo: Boitempo, 2010.

MILLER, David. Social Justice. Oxford: Oxford University Press, 1976.

SILVA, Enrico Paternostro Bueno da. A teoria social crítica de Nancy Fraser: Necessidade, feminismo e justiça. Dissertação (Mestrado em Sociologia). Campinas: Universidade Estadual de Campinas, 2013.

TRANSPARÊNCIA BRASIL. Excelências: Concessionários de Rádio/TV. Disponível em: <http://www.excelencias.org.br/@casa. php?banc=concessoes $>$. Acesso em 28 de dez. 2016. 